\title{
Identification of Differentially Up-regulated Genes in Apple with White Rot Disease
}

\author{
Yeo-Jin Kang ${ }^{1}$, Young Koung Lee ${ }^{2,3}$, and In-Jung Kim (iD ${ }^{1 *}$ \\ ${ }^{1}$ Faculty of Biotechnology, College of Applied Life Sciences, SARI, Jeju National University, Jeju 63243, Korea \\ ${ }^{2}$ Cold Spring Harbor Laboratory, Cold Spring Harbor, NY 11724, USA \\ ${ }^{3}$ Division of Biological Sciences and Institute for Basic Science, Wonkwang University, Iksan 54538, Korea
}

(Received on October 9, 2018; Revised on May 10, 2019; Accepted on June 27, 2019)

Fuji, a major apple cultivar in Korea, is susceptible to white rot. Apple white rot disease appears on the stem and fruit; the development of which deteriorates fruit quality, resulting in decreases in farmers' income. Thus, it is necessary to characterize molecular markers related to apple white rot resistance. In this study, we screened for differentially expressed genes between uninfected apple fruits and those infected with Botryosphaeria dothidea, the fungal pathogen that causes white rot. Antimicrobial tests suggest that a gene expression involved in the synthesis of the substance inhibiting the growth of $B$. dothidea in apples was induced by pathogen infection. We identified seven transcripts induced by the infection. The seven transcripts were homologous to genes encoding a flavonoid glucosyltransferase, a metallothionein-like protein, a senescence-induced protein, a chitinase, a wound-induced protein, and proteins of unknown function. These genes have functions related to responses to environmental stresses, including pathogen infections. Our results can be useful for the development of molecular markers for early detection of the disease or for use in breeding white rotresistant cultivars.

\footnotetext{
*Corresponding author.

Phone) +82-64-754-3357, FAX) +82-64-756-3351

E-mail) ijkim@jejunu.ac.kr

ORCID

In-Jung Kim

https://orcid.org/0000-0003-4554-4872

(c) This is an Open Access article distributed under the terms of the Creative Commons Attribution Non-Commercial License (http:// creativecommons.org/licenses/by-nc/4.0) which permits unrestricted noncommercial use, distribution, and reproduction in any medium, provided the original work is properly cited.
}

Articles can be freely viewed online at www.ppjonline.org.
Keywords : apple, Botryosphaeria dothidea, differentially expressed genes

Handling Editor : Jeon, Junhyun

Apple is an economically important crop as the apple cultivation area is the second largest and its production yield is the highest in Korea (Kim et al., 2010). More than 70\% of the fungicides used on apple farms are to control white rot disease and blotch disease (Jang et al., 2015). Botryosphaeria dothidea is a fungal pathogen that can infect a wide variety of tree and shrub species and is the cause of apple white rot disease. In apple, $B$. dothidea initially parasitizes the tree trunk, resulting in warts or ulcer symptoms, and subsequently forms primary conidiophores and cankers (Kim et al., 2001). Spores of B. dothidea are leaked by rainwater, scattered, and adhere to apple surfaces. Fruits can become infected after a relatively long incubation period resulting in white rot or bot rot disease (Kim and Kim, 1989; Zhao et al., 2016).

Since the end of the 1970s in Korea and China, apple diseases, including white rot disease, have caused a great economic damage to apple farmers due to the difficulties of disease control (Kim et al., 2016; Zhao et al., 2016). In recent years, in response to population increases and concerns over excessive use of pesticides (Lee et al., 2009), research has been focusing on the use of natural genetic resistance and the development of more environmentfriendly methods of disease control.

Apples are woody perennials with a complex genetic composition, making development of new varieties difficult. Furthermore, identification of genetic patterns has been slow and tedious because apple cultivation requires large land areas and efforts compared to other herbaceous crops. An entire breeding cycle takes more than 10 years 
(Kim et al., 2003). To overcome these limitations, indirect morphological markers or early selection markers based on biochemical characteristics that are highly correlated with the trait of interest have been used. However, these methods also have limited application due to the difficulty of isolating strongly related genes or the scarcity of useful markers (Kim and Hwang, 2004; Ludy and Shaw, 2001; Nybom, 1994).

The recent development of molecular biology and plant transformation technologies enabled introduction, editing, and regulation of specific genes in plants, providing a solution to the limitations mentioned above. In the field of molecular biology, genomics is the study of all genes in an organism and their various functions. Genomics has been applied to identify genes involved in specific functions and genes with differential expression patterns (Dougherty et al., 2018). Methods for identifying genes induced by pathogen infection include suppression subtraction hybridization (Gao et al., 2012), cDNA microarray (Okomo-Adhiambo et al., 2006), and differential display reverse transcriptionpolymerase chain reaction (DDRT-PCR) (Singh et al., 2013), annealing control primer (ACP) (Kim et al., 2004), and RNA sequencing (Shu et al., 2019). We choose ACP as a method that optimizes the cost and detection efficiency or sensitivity.

ACP systems can be used to identify differentially expressed genes (DEG), maximizes polymerase chain reaction (PCR) selectivity, and are safer than DDRT-PCR that uses radioisotopes (Hwang et al., 2004; Kim et al., 2004).

A
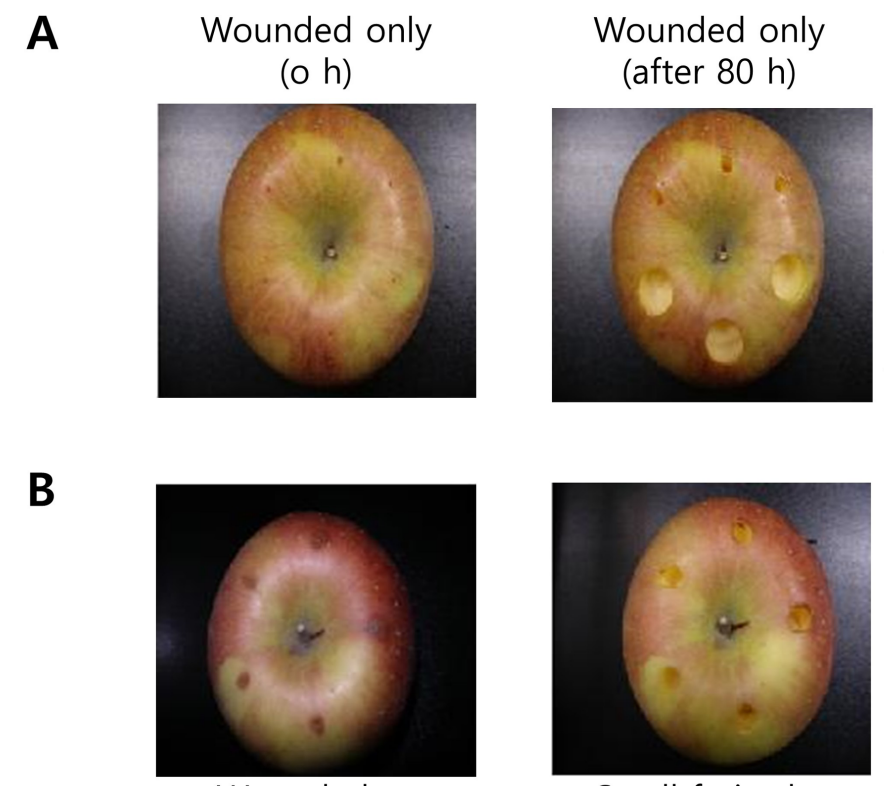

Wounded and infected (after $80 \mathrm{~h}$ )
Therefore, to investigate genes related to the resistance of apple to white rot disease occurring in fruit and stem, an ACP system was utilized.

Apples (Malus domestica cv. Fuji) were purchased from a local market. $B$. dothidea was isolated and identified from infected apples in a natural state at the National Institute of Horticultural and Herbal Science, Korea. Potato dextrose agar (PDA; Difco Co., Sparks, MD, USA) and potato dextrose broth (PDB; Difco Co.) were used as basic media for the cultivation of $B$. dothidea. The isolated $B$. dothidea were streaked on a plate with PDA medium. Colonies were inoculated into PDB medium and incubated at $27 \pm 1^{\circ} \mathrm{C}$ and $150 \mathrm{rpm}$.

The surfaces of Fuji apple fruits were washed with sterilized, double-deionized water (DDW), dried, and wounded $1 \mathrm{~mm}$ deep with a sterilized toothpick. The wounded areas were inoculated with $10 \mu \mathrm{l}$ spore suspension $\left(2 \times 10^{10} \mathrm{cfu} /\right.$ $\mathrm{ml}$ ) of $B$. dothidea (Fig. 1). After inoculation, fruits were placed in individual plastic containers containing $10 \mathrm{ml}$ of water without the wounds coming into contact with the water. Samples were collected after 4 days after incubation at $27 \pm 1^{\circ} \mathrm{C}$.

Antimicrobial tests were performed according to the method of Iwasa et al. (1971) with some modifications. The complex medium to evaluate antifungal activities was prepared by combining $450 \mathrm{ml}$ PDA and $50 \mathrm{ml}$ apple extract. Apple extracts were prepared from untreated apples, wounded apples, and infected apples. Fruit plugs $0.5 \mathrm{~cm}$ in diameter and $0.5 \mathrm{~cm}$ in depth encompassing the infected

\section{Large fruit plug (sample)}

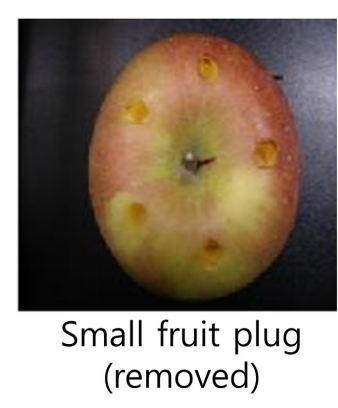

Fig. 1. Apple treatments by wounding and/or infection. The apple materials for apple extracts and RNA isolation were obtained using cork borers. (A) Apple fruits were wounded by toothpick. (B) Apple fruits were wounded and then infected with Botryosphaeria dothidea. After $78 \mathrm{~h}$ cultivation time, small fruit plugs of $0.5 \mathrm{~cm}$ in diameter and $0.5 \mathrm{~cm}$ in depth were removed and the large plugs of 2 $\mathrm{cm}$ in diameter and $0.5 \mathrm{~cm}$ in depth were sample for water extraction and RNA isolation. 
portions and equivalent wounded or unwounded portions were removed using a cork borer. The apple material used for the extraction was obtained using a larger cork borer that cut plugs $2 \mathrm{~cm}$ in diameter and $0.5 \mathrm{~cm}$ in depth. The plugs were combined to obtain $5 \mathrm{~g}$, ground in a blender containing $50 \mathrm{ml} \mathrm{DDW}$, and filtered using $6 \mu \mathrm{m}$ filter paper (Advantec, Toyo, Japan) of B. dothidea. Each apple extract was mixed with PDA medium. Five-millimeter-diameter mycelial plug was placed on the center of a plate. Cultivation was performed at $27 \pm 1^{\circ} \mathrm{C}$ for $78 \mathrm{~h}$. The growth diameter was measured.

Statistical comparisons were made by analysis of variance (ANOVA) procedure followed by a Duncan's multiple range tests (SPSS version 12.0, SPSS Inc., Chicago, IL, USA). $P<0.05$ was considered significantly different.

Total RNA was extracted from plugs obtained from normal, wounded, and wounded and B. dothidea-infected apple fruits using the separation method described in $\mathrm{Hu}$ et al. (2002). Isolated RNA was quantified using a spectrophotometer and used to screen for DEGs using an ACP system and reverse transcription-polymerase chain reaction (RTPCR).

Total RNAs extracted from apple fruits were used for the synthesis of first-strand cDNAs by reverse transcription. Reverse transcription was performed for $1.5 \mathrm{~h}$ at $42^{\circ} \mathrm{C}$ in a final reaction volume of $20 \mu \mathrm{l}$ containing $3 \mu \mathrm{g}$ of the purified total RNA, $4 \mu \mathrm{l}$ of $5 \times$ reaction buffer (Promega, Madison, WI, USA), $5 \mu 1$ of dNTPs (each $2 \mathrm{mM}$ ), $2 \mu 1$ of $10 \mu \mathrm{M}$ dT-ACP1 (5'-CTGTGAATGCTGCGACTACGATIIIIIT-3'), 0.51 of RNasin RNase Inhibitor (40 U/ $\mu \mathrm{l}$, Promega), and $1 \mu \mathrm{l}$ of Moloney murine leukemia virus reverse transcriptase (200 U/ $\mu 1$, Promega). First-strand cDNAs were diluted by the addition of $80 \mu$ of ultra-purified water and stored at $-20^{\circ} \mathrm{C}$ until use.

DEGs between wounded apple fruit and apple fruits wounded and infected with $B$. dothidea were screened by an ACP-based PCR method using the GeneFishing DEG kits (Seegene, Seoul, Korea) according to the manufacturer's manual (Kim et al., 2004; Pohjanvirta, 2004). The amplified PCR products were separated on $2 \%$ agarose gels stained with ethidium bromide and then the band intensities were analyzed by Gel Doc system (Bio-Rad, Hercules, CA, USA).

The differentially expressed DNAs separated on agarose gels were extracted using GENCLEAN II Kits (Qbiogene, Carlsbad, CA, USA), and directly cloned into a TOPO TA cloning vector (Invitrogen, Carlsbad, CA, USA) according to the manufacturer's instructions. The cloned plasmids were sequenced on an ABI PRISM 3100 Genetic Analyzer (Applied Biosystems, Foster City, CA, USA) using M13 forward primer (5'-CGCCAGGGTTTTCCCAGTCACGA-3') or M13 reverse primer (5'-AGCGGATAACAATTTCACACAGGA-3'). The determined nucleotide sequences were identified using the blast searches of NCBI (http://www.ncbi.nlm.nih.gov/blast/) to compare the homology of the genes.

To confirm the differential expression of the isolated genes, we performed RT-PCR with specific PCR primers (Table 1) designed from the determined nucleotide sequences. 18S rRNA was used as a control.

Antimicrobial tests were performed to investigate the induction of resistance to infection with $B$. dothidea (Fig. 2). Four types of samples were prepared: plates containing PDA only (PDA-only), plates containing normal apple extract in PDA (PDA-untreated), plates containing woundedapple extract in PDA (PDA-wounded), and plates containing wounded- and infected-apple extract in PDA (PDAinfected). The diameter of fungal growth was the smallest in PDA-only medium without apple extract $(P<0.05)$. This may be because various ingredients, such as sugars in apple extract, promoted the growth of fungi in PDAuntreated, PDA-wounded, and PDA-infected samples. However, the fungal growth diameter of the PDA-infected samples was smaller than the diameter of the PDA-wound-

Table 1. Primer sets for competitive RT-PCR

\begin{tabular}{lll}
\hline Clone & \multicolumn{1}{c}{ Forward primer } & \multicolumn{1}{c}{ Reverse primer } \\
\hline DEG6 & 5'-AAGAACCACCATCCACCAAG & 5'-TGGATGGCTTCTCGGATATT \\
DEG12 & 5'-TGCAAATTCAAAAGCCCATA & 5'-TTCCCTCTTCAGGTTCTGGA \\
DEG16 & 5'-ACCACGAACATGGCGATTAT & 5'-GCTGCACCTGTGGTCACTAA \\
DEG19 & 5'-AGCGACGAAGGAAGCTACTG & 5'-AGCAAGGCCAAAAAGTCATC \\
DEG32 & 5'-TGATGCGTCATCATCCCTAA & 5'-CGATTAAGAATTCGCCCAAG \\
DEG35 & 5'-CACCACCAGAAGTTCAGCAA & 5'-ATCCACCACCTCTCTGTTGG \\
DEG37 & 5'-CATGGTTACACCCAACACCA & 5'-GGTCCTGTGCAGTGGAGTCT \\
18S rRNA & 5'-CCGCTAACAGCAAAGGATCT & 5'-CCTGGTAAGTTTCCCCGTGTTG \\
\hline
\end{tabular}

RT-PCR, reverse transcription-polymerase chain reaction. 


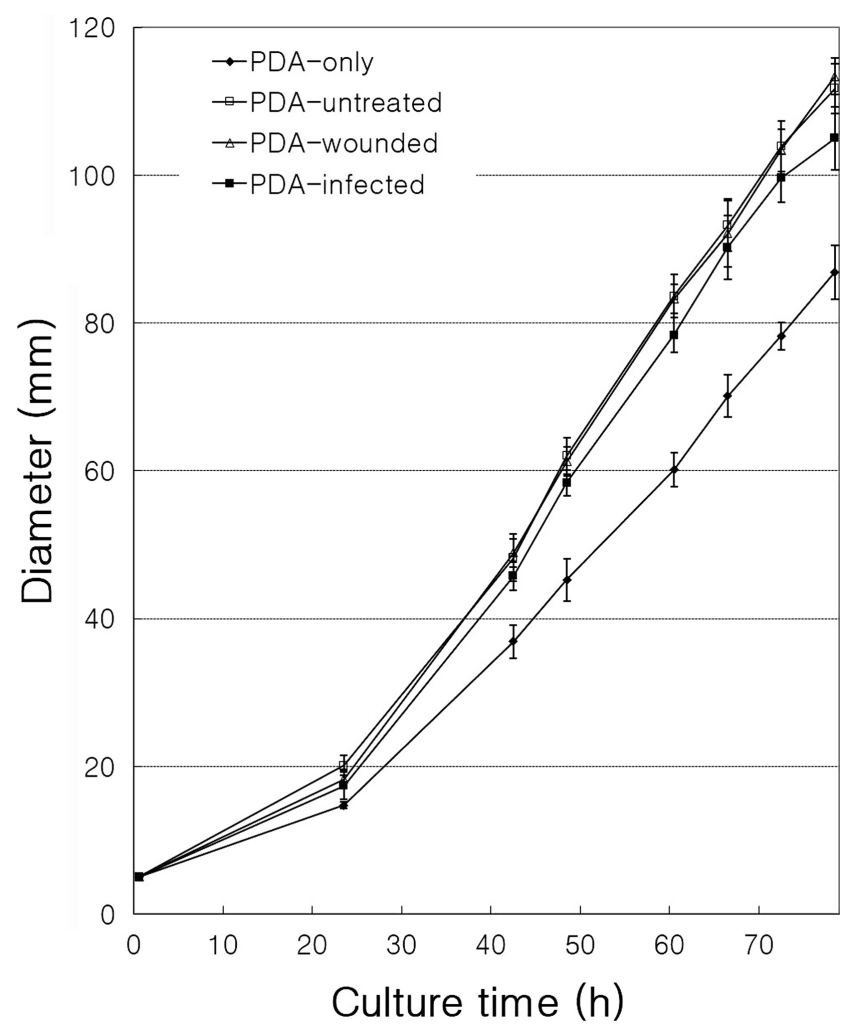

Fig. 2. Effect of apple extract on the growth of Botryosphaeria dothidea. The effect on $B$. dothidea growth by different apple extracts (potato dextrose agar [PDA]-untreated, PDA-wounded, and PDA-infected) and without any apple extract (PDA-only) for $78 \mathrm{~h}$. Data represent the means \pm standard errors from three individual experiments.

ed and PDA-untreated samples $(P<0.05)$. The diameters of PDA-wounded and PDA-untreated samples were very similar in size (Fig. 2). These results suggest that biosynthesis of substances inhibiting the growth of fungi in apples was induced by pathogen infection. Thus, production of a resistance substance in response to the infection suggests that a gene expression involved in the synthesis of the substance was induced in the fruit.

We analyzed genes induced by infection with $B$. dothidea by using an ACP-based DEG screening method. For this, 1-mm-deep wounds were applied to the surface of apples and subsequently inoculated with white rot fungi. As a control, apples that were equally wounded without pathogenic inoculation were also used. Thirty-four genes showing distinct expression differences (2-fold cut-off) between the infected and uninfected samples were identified. Out of those genes, seven genes were up-regulated in the infected samples compared to the uninfected samples (Fig. $3)$. We focused on the genes that were up-regulated following infection because it has been hypothesized that the resistance gene would be induced in the infected sample based on the gene-for-gene hypothesis described previously (Flor, 1971; Martin, 1999). Thus, these seven genes were isolated, subcloned, and sequenced to determine if they may be involved in the resistance response (Fig. 4).

DNA sequences were analyzed using BLAST (Basic Local Alignment Search Tool) software. The nucleotide sequences of the seven genes isolated through the DEG screening method were compared with the gene information registered with NCBI through the BlastX and BlastN programs. The DEGs were identified based on their homology to known gene sequences (Table 2). The sequences of DEG6, DEG16, and DEG32 had high homologies with the sequences for flavonoid glucosyltransferase (FGT), metallothionein-like protein, and senescence-related protein chitinase, respectively. DEG19 and DEG37 had senescence-inducible protein and wound-induced protein, respectively. However, the other DEG clones had high homologies to unidentified genes. Following homology searches for these genes, physiological functions were deduced through analysis of the literature.

The DEG6 clone is highly homologous to FGT. Disease

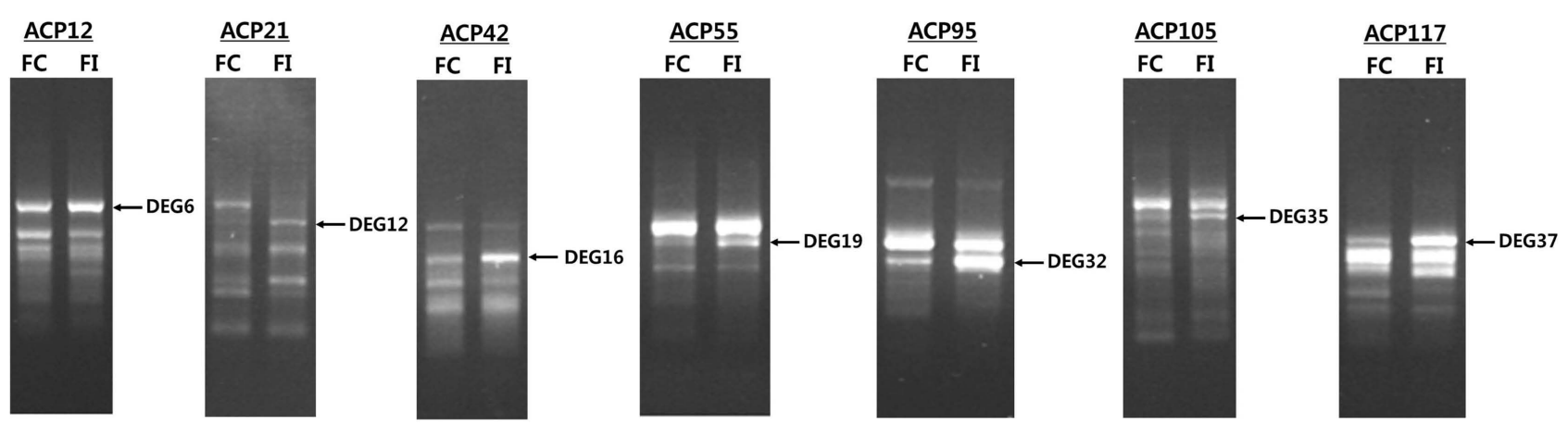

Fig. 3. Screening of differentially overexpressed genes (differentially expressed gene [DEG] 6, 12, 16, 19, 32, 35, and 37) in infected fruit (FI) compared to wounded fruits (FC) using GeneFishing DEG polymerase chain reaction using arbitrary annealing control primers (ACPs) (ACP12, ACP21, ACP42, ACP55, ACP95, ACP105, and ACP117). 


\section{DEG6}

GTTTTTGTGGTCCCTACGCCGGCCCCCACCTAATGGCCAGAGAGCTATGCCAAGAGACTACGAGGATCTAAAGGCAGTCTTGCCCGAAGGGTTTCTTGATCGGACGGCTACGGTTGGGAAGGTGATTGGTTGGGCCCCGCAAGCGGCAATCCTAGGCCATCCGGCAACCGGAGGGTTTGTATCACATTGCGGGTGGAATTCTACGTTGGAAAGTTTATGGAATGGCGTGCCGATCGCCGCATGGCCAATGTACGCGGAGCAAAACCTGAATGCCTTTCAGTTGGTGGTGTAGTTGGGATTGGCAGTGGAGATTAAGATGGATTATAGGAAGGACAGCGACGTGGTGGTGAGTGCAGAAGACATAGAAAGAGGGATAAGGCAAGTGATGGAGCTTGACAGTGATGTAAGGAAAAGAGTGAAGGAGATGAGTGAAAAGAGCAAGAAAGCCTTGGTGGATGGTGGTTCTTCTTACTCTTCATTAGGGCGTTTTATTGATCAAATTTAATTGGGTTGGGGGGGGGCTTTTATATTCTCCTCGCTTATTTTTACGTTATGTAATTTGCAATGTTTGTATTGTAAGTTTTTCGTTGTAATACATAGTTCAACATATCAAATCTCAAAATCTTGTGGT

\section{DEG12}

AATCGGAAAAATGTATCTTTATATATTCTCATATAACAGCGCTACAAATTTATAAATTATGAAATATAAATGAATAAATAAATGAATTTAGTACAATAATAAATGCAAATTCAAAAGCCCATAAACACCCCCACTCTACATAACAATGACTGCAGCGAAACTCCAACAGCTAGAGCTCCGGCGGCGGAGAACCGATTCAAAACGGCACCGTTAGCAGGAGCGGGAGCATCGGAGGGAGATCCAGAACCTGAAGAGGGAACAGTCGCCGCCGCCGGAGACGACGATGGGGCAGAAGGTGGAGAGTCGGGGACGGGAGATGTGGAAGGAGAAGCCGATGGTGAAGT

\section{DEG16}

CATAACATCACAAGACCACGAACATGGGGATTATATGACACAATCACAGAACATAGTGACAGGTTTTCACAGACACTACATGTCACTCAACAGACACAAATACTATAAACAAACCAAAGACAAAGCCACAACGTTGTTTTCCCACAAACACTTTATTCGTTTACATCTTTAATTTGGTTGTATGGGTTTAGTGACCACAGGTGCAGCTCACACATGAGCAGCCTGTGCCACACTTGCACTTTCCGTCGTGCTCGGCGGCAGGAGCATCC

\section{DEG19}

ATTGTAATATAGCTTATTTTTATAAATAAAATAGAGGATTAAACGATATTAATTCTCGGAAATGACTGCTAAGCTTAAGCGACGAAGGAGGTACTGCTACTAGTGCGGAGATGAGCCCAACGAAAGAACCAAGAGTGGTGGTAGTGAGAGATGAAGCATGGGAGGATGATGGTGGAGGAGCCAACAGAGAANAGgTGGTGGTTGGTGATCCAACGGTGATGATGACTTTTTGGCCTTGCTCGCAGTGGTTACCAA

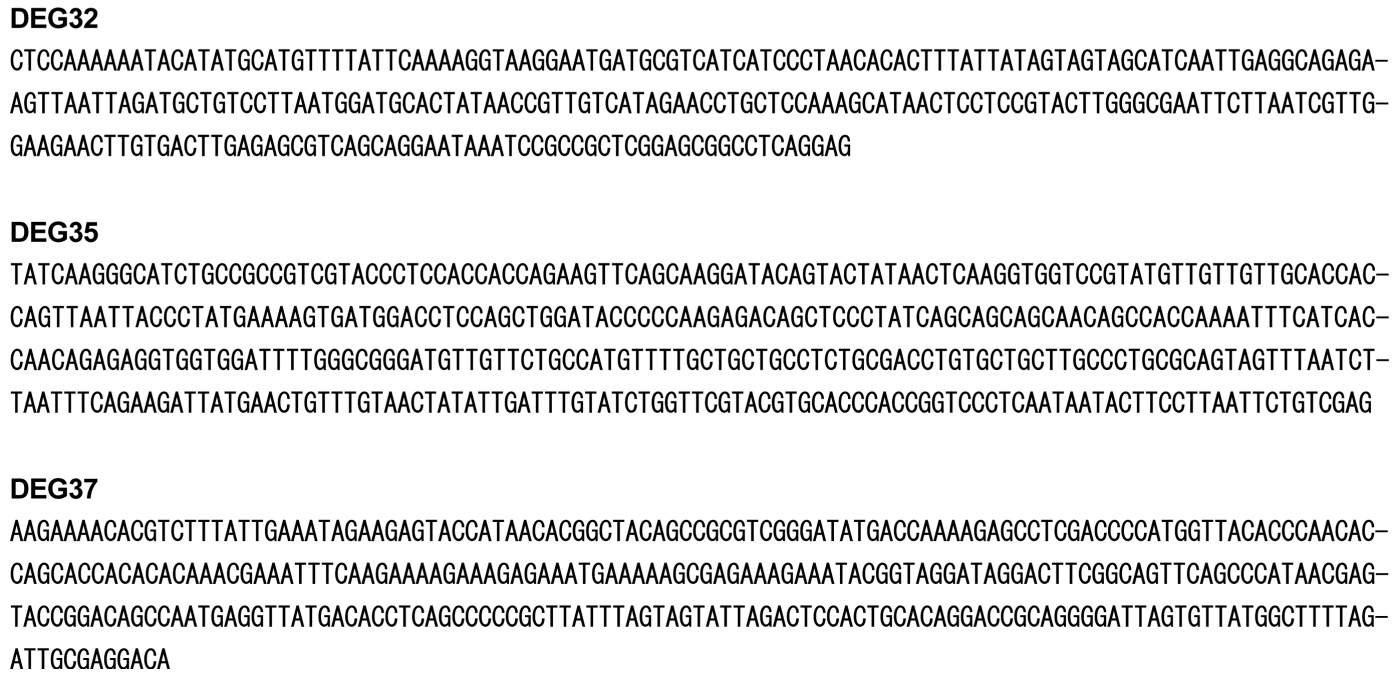

\section{DEG35}

TATCAAGGGCATCTGCCGCCGTCGTACCCTCCACCACCAGAAGTTCAGCAAGGATACAGTACTATAACTCAAGGTGGTCCGTATGTTGTTGTTGCACCACCAGTTAATTACCCTATGAAAAGTGATGGACCTCCAGCTGGATACCCCCAAGAGACAGCTCCCTATCAGCAGCAGCAACAGCCACCAAAATTTCATCACCAACAGAGAGGTGGTGGATTTTGGGCGGGATGTTGTTCTGCCATGTTTTGCTGCTGCCTCTGCGACCTGTGCTGCTTGCCCTGCGCAGTAGTTTAATCTTAATTTCAGAAGATTATGAACTGTTTGTAACTATATTGATTTGTATCTGGTTCGTACGTGCACCCACCGGTCCCTCAATAATACTTCCTTAATTCTGTCGAG

\section{DEG37}

AAGAAAACACGTCTTTATTGAAATAGAAGAGTACCATAACACGGCTACAGCCGCGTCGGGATATGACCAAAAGAGCCTCGACCCCATGGTTACACCCAACACCAGCACCACACACAAACGAAATTTCAAGAAAAGAAAGAGAAATGAAAAAGCGAGAAAGAAATACGGTAGGATAGGACTTCGGCAGTTCAGCCCATAACGAGTACCGGACAGCCAATGAGGTTATGACACCTCAGCCCCCGCTTATTTAGTAGTATTAGACTCCACTGCACAGGACCGCAGGGGATTAGTGTTATGGCTTTTAGATTGCGAGGACA

Fig. 4. Nucleotide sequences of the seven apple genes up-regulated in response to Botryosphaeria dothidea infection.

resistance is lowered in tobacco leaves following reduced expression of FGT (Chong et al., 2002). Furthermore, FGT functions in disease resistance in tomato plants (LangloisMeurinne et al., 2005).

The sequence of DEG16 was consistent with metallothionein-like protein. Metallothionein-like protein is induced in Nicotiana glutinosa L. following infection with tobacco mosaic virus and wounding (Choi et al., 1996). Therefore, metallothionein-like gene may also function in disease resistance to $B$. dothidea infection in apple.

DEG32 clone showed high homology with chitinase. Fukuda and Shinshi (1994) reported that the chitinase gene is similar to the pathogenesis-related protein and is expressed by the invasion of pathogens. In addition, chitinase degrades the cell wall of pathogens and exerts antimicrobial activity (Mahesh et al., 2017).

DEG19 and DEG37 clones did not match known genes. These clones showed the homology with stress-relating 
Table 2. Identification of DEGs based on the homology of cDNA fragments with known sequences in the NCBI data base

\begin{tabular}{|c|c|c|c|c|}
\hline $\begin{array}{l}\text { DEG } \\
\text { clone }\end{array}$ & $\begin{array}{l}\text { DEG clone } \\
\text { size (bp) }\end{array}$ & Sequence homology search & $\begin{array}{l}\text { Identities, } \\
\mathrm{n}(\%)\end{array}$ & $\begin{array}{c}\text { GenBank } \\
\text { accession No. }\end{array}$ \\
\hline DEG6 & 631 & Malus $\times$ domestica clone 30-4 flavonoid glucosyltransferase mRNA & $172 / 187(91)$ & AY347790.1 \\
\hline DEG12 & 345 & Malus $\times$ domestica cDNA clone AASB004227, mRNA & $330 / 344(95)$ & CN883837.1 \\
\hline DEG16 & 270 & $\begin{array}{l}\text { Malus } \times \text { domestica metallothionein-like protein (AMT2) mRNA, } \\
\text { complete cds }\end{array}$ & $270 / 270(100)$ & MDU61974 \\
\hline DEG19 & 256 & $\begin{array}{l}\text { Malus } \times \text { domestica } \text { cDNA clone AARA014034HT(AA RA) Royal } \\
\text { Gala partially senescing leaf Malus } \times \text { domestica } \text { cDNA clone } \\
\text { AARA01434, mRNA }\end{array}$ & $141 / 143(98)$ & CN878543.1 \\
\hline DEG32 & 266 & $\begin{array}{l}\text { Malus } \times \text { domestica cDNA clone Mdfw2031113 5' similar chitinase, } \\
\text { mRNA }\end{array}$ & $266 / 266(100)$ & CN581151.1 \\
\hline DEG35 & 399 & Malus $\times$ domestica cDNA clone AARA011358, mRNA & $398 / 398(100)$ & CN877405.1 \\
\hline DEG37 & 317 & $\begin{array}{l}\text { Malus } \times \text { domestica } \text { cDNA clone Mdlv4-4045p07 5' similar to } \\
\text { wound-induced protein } 1 \text {, mRNA }\end{array}$ & $154 / 154(100)$ & CX022933.1 \\
\hline
\end{tabular}

DEG, differentially expressed gene.

genes. The DEG19 clone showed high homology with genes induced by senescence, an internal stress response process. Both wounding and infection are stress for plants. Thus DEG19 clone might be a common gene in the stress response. DEG37 clone showed high homology with wounding-induced protein. These results suggest that the DEG37 clone is a gene whose expression is induced by a wound, but the expression is further increased by pathogen infection (Fig. 5). B. dothidea, a white rot pathogen, penetrates wounded areas and grows when the proper environmental conditions are established to form a lesion (Kim et al., 2016). Therefore, it can be deduced that the pathogen in the injured area induced the expression of DEG37 by expanding the wound area through proliferation.

To confirm the induction of the isolated genes, semiquantitative RT-PCR was performed using total RNA extracted from wounded apple fruits uninfected or infected with $B$. dothidea (Fig. 5). We confirmed that the seven isolated genes were overexpressed in the infected apples compared to uninfected apples; thus, the expression was induced by the pathogen infection. Therefore, these genes may function as molecular markers for early detection of the disease or for breeding white rot-resistant cultivars.

Our results indicate that some genes are up-regulated in
A

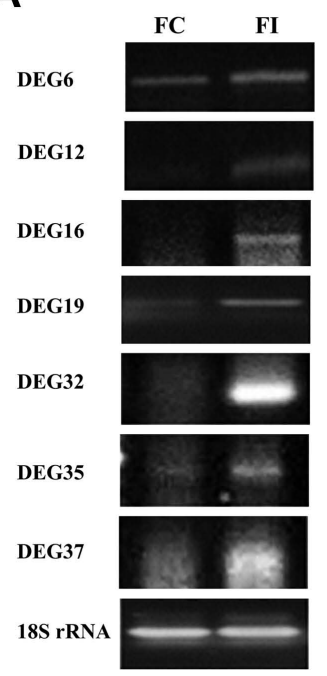

B

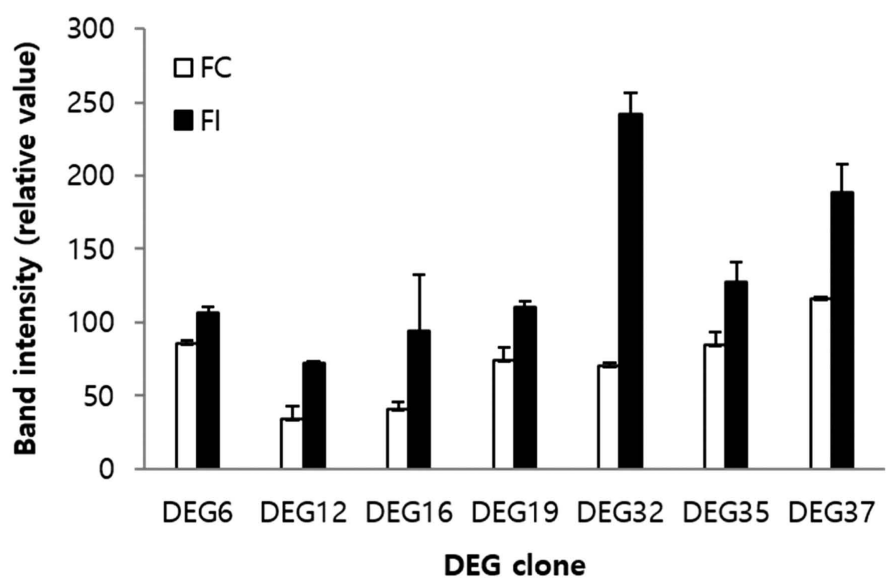

Fig. 5. Comparison of expression levels of DEGs in control fruit (FC) and infected fruit (FI) using competitive reverse transcriptionpolymerase chain reaction (RT-PCR) with gene-specific primers (Table 1). (A) Agarose gel electrophoresis of RT-PCR products. (B) Relative amount of RT-PCR product. Data represent the means \pm standard errors from three individual experiments. 
apple in response to $B$. dothidea infection within the injured area. Some of the genes might play an important role in resistance to apple white rot (Scheel, 1998; Somssich and Hahlbrock, 1998). Thus, these genes may be useful for early warning of the disease or for breeding apples that are resistant to white rot disease through breeding processes such as classical and biotechnological breeding through further studies.

Most of the up-regulated genes that were identified here are known to be induced in response to internal and external stress and are closely related to disease resistance. These results indicate that our ACP-based DEG screening experiment was successfully performed and that the isolated genes could be used as molecular markers of disease resistance. Our results provide basic information to assist in the development of systematic disease resistance breeding systems using molecular markers.

\section{Acknowledgments}

This research was supported by the 2018 scientific promotion program funded by Jeju National University.

\section{References}

Choi, D., Kim, H. M., Yun, H, K., Park, J. A., Kim, W. T. and Bok, S. H. 1996. Molecular cloning of a metallothioneinlike gene from Nicotiana glutinosa L. and its induction by wounding and tobacco mosaic virus infection. Plant Physiol. 112:353-359.

Chong, J., Baltz, R., Schmitt, C., Beffa, R., Fritig, B. and Saindrenan, P. 2002. Downregulation of a pathogen-responsive tobacco UDP-Glc:phenylpropanoid glucosyltransferase reduces scopoletin glucoside accumulation, enhances oxidative stress, and weakens virus resistance. Plant Cell 14:1093-1107.

Dougherty, L., Singh, R., Brown, S., Dardick, C. and Xu, K. 2018. Exploring DNA variant segregation types in pooled genome sequencing enables effective mapping of weeping trait in Malus. J. Exp. Bot. 69:1499-1516.

Flor, H. H. 1971. Current status of the gene-for-gene concept. Annu. Rev. Phytopathol. 9:275-296.

Fukuda, Y. and Shinshi, H. 1994. Characterization of a novel cisacting element that is responsive to a fungal elicitor in the promoter of a tobacco class I chitinase gene. Plant Mol. Biol. 24:485-493.

Gao, M., Wang, Q., Wan, R., Fei, Z. and Wang, X. 2012. Identification of genes differentially expressed in grapevine associated with resistance to Elsinoe ampelina through suppressive subtraction hybridization. Plant Physiol. Biochem. 58:253268.

Hu, C. G., Honda, C., Kita, M., Zhang, Z., Tsuda, T. and Moriguchi, T. 2002. A simple protocol for RNA isolation from fruit trees containing high levels of polysaccharides and polyphenol compounds. Plant Mol. Biol. Rep. 20:69.

Hwang, K.-C., Cui, X.-S., Park, S.-P., Shin, M.-R, Park, S.-Y., Kim, E.-Y. and Kim, N.-H. 2004. Identification of differentially regulated genes in bovine blastocysts using an annealing control primer system. Mol. Reprod. Dev. 69:43-51.

Iwasa, T., Higashide, E. and Shibata, M. 1971. Studies on validamycins, new antibioteics. III. Bioassay methods for the determination of validamycin. J. Antibiot. 14:114-118.

Jang, I., Kim, H.-M., Lee, S.-W., Choi, K.-H. and Suh, S. J. 2015. Analysis of pesticide applications on apple orchards in Geochang, Korea. Korean J. Pestic. Sci. 19:93-100.

Kim, D.-I. and Hwang, J.-H. 2004. Inheritance and RAPD marker selection linked to resistance trait of alternaria blotch $(A$. mail) in apples. Korean J. Hortic. Sci. Technol. 22:315-320.

Kim, K. W., Kim, K. R. and Park, E. W. 2016. Effects of interrupted wetness periods on conidial germination, germ tube elongation and infection periods of Botryosphaeria dothidea causing apple white rot. Plant Pathol. J. 32:1-7.

Kim, K. W., Park, E. W., Kim, Y. H., Ahn, K.-K., Kim, P. G. and Kim, K. S. 2001. Latency- and defense-related ultrastructural characteristics of apple fruit tissues infected with Botryosphaeria dothidea. Phytopathology 91:165-172.

Kim, M. Y., Song, K. J., Hwang, J.-H., Shin, Y.-U. and Lee, H. J. 2003. Development of RAPD and SCAR markers linked to the Co gene conferring columnar growth habit in apple (Malus pumila Mill). J. Hortic. Sci. Biotechnol. 78:512-517.

Kim, S. B. and Kim, C. S. 1989. Studies on the pathogenicity and the ecology of apple rot caused by Botryosphaeria dothidea. J. Korean Soc. Hortic. Sci. 30:285-293.

Kim, S.-Y., Heo, I.-H. and Lee, S.-H. 2010. Impacts of temperature rising on changing of cultivation area of apple in Korea. $J$. Korean Assoc. Reg. Geogr. 16:201-215.

Kim, Y.-J., Kwak, C.-I., Gu, Y.-Y., Hwang, I.-T. and Chun, J.-Y. 2004. Annealing control primer system for identification of differentially expressed genes on agarose gels. BioTechniques 36:424-426, 428, 430.

Langlois-Meurinne, M., Gachon, C. M. M. and Saindrenan, P. 2005. Pathogen-responsive expression of glycosyltransferase genes $U G T 73 B 3$ and $U G T 73 B 5$ is necessary for resistance to Pseudomonas syringae pv tomato in Arabidopsis. Plant Physiol. 139:1890-1901.

Lee, D. H., Shin, H. C., Cho, R. H. and Uhm, J. Y. 2009. Reducing fungicidal spray frequency for major apple diseases by increasing the spray interval from 15 to 25 days. Plant Pathol. J. 25:270-279.

Ludy, J. J. and Shaw, D. V. 2001. Dose marker-assisted selection make dollars and sense in a fruit breeding program? HortScience 36:872-879.

Mahesh, H. M., Murali, M., Anup Chandra Pal, M., Melvin, P. and Sharada, M. S. 2017. Salicylic acid seed priming instigates defense mechanism by inducing PR-proteins in Solanum melongena L. upon infection with Verticillium dahliae Kleb. Plant Physiol. Biochem. 117:12-23. 
Martin, G. B. 1999. Functional analysis of plant disease resistance genes and their downstream effectors. Curr. Opin. Plant Biol. 2:273-279.

Nybom, H. 1994. DNA fingerprinting: a useful tool in fruit breeding. Euphytica 77:59-64.

Okomo-Adhiambo, M., Beattie, C. and Rink, A. 2006. cDNA microarray analysis of host-pathogen interactions in a porcine in vitro model for Toxoplasma gondii infection. Infect. Immun. 74:4254-4265.

Pohjanvirta, R. 2004. Comparison of several hot-start Tag DNA polymerases for detection of differentially expressed genes by GeneFishing. Biochemica 2:17-18.

Scheel, D. 1998. Resistance response physiology and signal transduction. Curr. Opin. Plant Biol. 1:305-310.

Shu, C., Zhao, M., Anderson, J. P., Garg, G., Singh, K. B., Zheng,
W., Wang, C., Yang, M. and Zhou, E. 2019. Transcriptome analysis reveals molecular mechanisms of sclerotial development in the rice sheath blight pathogen Rhizoctonia solani AG1-IA. Funct. Integr. Genomics 19:743-758.

Singh, N. K., Kumar, K. R. R., Kumar, D., Shukla, P. and Kirti, P. B. 2013. Characterization of a pathogen induced thaumatinlike protein gene AdTLP from Arachis diogoi, a wild peanut. PLoS ONE 8:e83963.

Somssich, I. E. and Hahlbrock, K. 1998. Pathogen defense in plants: a paradigm of biological complexity. Trends Plant Sci. 3:86-90.

Zhao, X., Zhang, G.-L., Li, B.-H., Xu, X.-M., Dong, X.-L., Wang, C.-X. and Li, G.-F. 2016. Seasonal dynamics of Botryosphaeria dothidea infections and symptom development on apple fruits and shoots in China. Eur. J. Plant Pathol. 146:507-518. 